\title{
Relação entre fabricante e varejista: um estudo qualitativo comparativo no setor de peças automotivas
}

\author{
Manufacturer and retailer relationship: a qualitative \\ and comparative study in the automotive sector
}

\begin{abstract}
Resumo
Este trabalho tem como objetivo analisar diferentes abordagens de aliança estratégica entre fabricante e varejista durante o período de 1995 a 2015, sob a perspectiva do fabricante. Os pressupostos teóricos tomaram como base o trabalho de Coghlan et al. (2012), em relação às características dos canais de marketing, além do trabalho de Frazier (1999), que contempla o tema da gestão dos canais de distribuição. Trata-se de estudo exploratório, ancorado por abordagem qualitativa. Os dados foram coletados por meio de entrevista e de análise documental. Os resultados evidenciaram que, no cenário estudado, o fabricante valoriza a cultura de compreensão, respeito e confiança (mediado pela cultura interna), enquanto que outros tendem a não praticar essa relação. Concluiu-se que a recompensa financeira não desempenha papel fundamental na aliança estratégica para o varejista se comparada com suporte, relacionamento e confiança.
\end{abstract}

Palavras-chave: fabricante; aliança estratégica; varejo.

\begin{abstract}
This paper aims to analyze and present the different approaches of strategic alliance between manufacturer and retailer from 1995 to 2015, from the manufacturer's perspective. As a conceptual field, the assumptions of Coghlan et al. (2012) about the marketing scenario have been taken as the main contribution. Also, the work of Frazier (1999) about distribution channels has guided the research as a theoretical background. With a qualitative approach, this exploratory study made use of interviews and documents as data sources. The results showed that, in the scenario studied, the manufacturer values the culture of comprehension, respect and trust while others tend not to do the same. As conclusions, the study allows some inferences such as, for the retailer, financial reward does not play a fundamental role in strategic alliance when compared to support, partnership and reliability.
\end{abstract}

Keywords: manufacturer; strategic alliance; retail.

Laudelino S. A. Sanematsu

Mestrando em Administração

Universidade Metodista de São Paulo - Brasil

laudelinosanematsu@gmail.com

Ana R. Silva

Mestranda em Administração

Universidade Metodista de São Paulo - Brasil

aninharosa@globo.com

Almir M. Vieira

Doutor em Educação

Universidade Metodista de São Paulo - Brasil

almir.vieira@gmail.com 


\section{INTRODUÇÃO}

Questões estratégicas e seus desdobramentos são vistos como sobrevivência e crescimento empresarial frente ao plano de atuação de uma empresa (Dickson, 2001). Em outra visão, Porter (2002, p. 28) afirma que a "estratégia consiste em criar posição competitiva exclusiva e sustentável, difícil de imitar". O autor afirma que as empresas devem refletir sobre o modo pelo qual pretendem se diferenciar dos concorrentes, de forma a alcançar os objetivos.

Frente a esse desafio, surgem os canais de distribuição que, no passado, tiveram pouca atenção se comparados ao mix produto, preço e promoção (Rosenbloom, 2002). Segundo o autor, canais de marketing (distribuição) geram vantagem competitiva sustentável, pois não são facilmente copiados pela concorrência, diferentemente do que acontece com as estratégias de produto, preço e promoção da concorrência.

Embora vários temas sejam tratados dentro do canal marketing frente à criação e geração de vantagem competitiva, alianças estratégicas e suas relações têm sido assunto recorrente (Gulati, 1998; Heimerikes, \& Duysters, 2007; Werner, 2002). Segundo Coughlan, Anderson, Stern e El-Ansary (2012, p. 234), os “membros do canal se comprometem na expectativa racional de obter recompensas financeiras". Assim, para que o relacionamento de comprometimento se crie e se mantenha, é necessário que a satisfação econômica aconteça, pois desempenha papel fundamental (Ganesan, 1994).

Outra justificativa para se criar e se manter a relação de comprometimento é a capacidade de gerar coesão, redução de custos, agregar valor ao produto e ao serviço ou aumentar as vendas (Ansoff, 1988; Porter, 1988; Kotler, 1993; Kato, 2004), de forma a melhorar o atendimento aos clientes e aumentar as oportunidades de negócios entre membros do canal de marketing (Coughlan et al., 2012), visando à manutenção da vantagem competitiva (Sanematsu, \& Souza, 2014).

Diante deste contexto, o presente estudo tem como objetivo analisar diferentes abordagens de aliança estratégica entre fabricante e varejista durante o período de 1995 a 2015, sob a perspectiva do fabricante, considerando-se uma análise longitudinal. Para tanto, o trabalho é composto de cinco partes, incluindo esta introdução. Na segunda, é apresentado o campo conceitual assumido, seguido pela parte dos procedimentos metodológicos. Na parte seguinte, consta a apresentação dos dados, bem como a análise dos resultados. Na última parte, algumas considerações finais são registradas, com indicação para estudos futuros.

\section{REFERENCIAL TEÓRICO}

\subsection{Estratégia de marketing de difícil imitação (praça)}

Ao abordar as estratégias de marketing na literatura (Mccarthy, \& Perreault, 1997; Churchill Jr., \& Peter, 2000; Dickson, 2001; Berkowitz, 2003; Limeira, 2003; Blythe, \& Zimmerman, 2005; Kotler, \& Keller, 2013), é possível identificar uma série de conceitos complementares, circulando de forma satélite, no campo de estratégia.

Para Dickson (2001), questões estratégicas são vistas como sobrevivência, e o crescimento empresarial, em face de um plano de atuação da empresa. Em outra visão, Porter (2002, p. 28) afirma que a "estratégia consiste em criar posição competitiva exclusiva e sustentável, difícil de imitar". Conforme o autor, as empresas devem pensar de que maneira pretendem se diferenciar das outras para o alcance dos objetivos organizacionais.

Assim, tão importante quanto alcançar uma vantagem competitiva é sustentá-la (Sanematsu, \& Souza, 2014) em ambientes permeados por rápidas mudanças. Nesse contexto surgem os canais de marketing (praça) como estratégia, que no passado, receberam pouca atenção em relação mix preço, produto e promoção (Rosenbloom, 2002). Segundo o autor, canais de marketing (distribuição) geram vantagem competitiva sustentável, pois não são facilmente copiados pela concorrência, diferentemente se comparado às estratégias de produto, preço e promoção da concorrência. Na mesma perspectiva, Miranda e Joshi (2003) apontam o planejamento, a organização, o controle e as alianças estratégicas os principais elementos dos canais de distribuição.

\subsection{Função do canal de marketing}

O canal de marketing (ou canal de distribuição) é definido por Rosenbloom (2002, p. 27) como "a organização contratual externa que a administração opera para alcançar seus objetivos de distribuição". Já Kotler e Keller (2013, p. 448) afirmam que "canais de distribuição são conjuntos de organizações interdependentes envolvidas no processo de disponibilizar um bem ou serviço para uso ou consumo". Para Coughlan et al. (2012, p. 2), trata-se de "um conjunto de organizações interdependentes envolvidas no processo de tornar um produto ou serviço disponível para uso ou consumo". Portanto, é uma operação que ocorre fora da organização, administrada por intermediários com funções de negociação, venda e transferência, ou seja, "do produtor para o seu usuário 
final" (Rosenbloom, 2002, p. 27).

Coughlan et al. (2012, p. 7), em vez de função, utilizam o termo fluxo para realçar que "esses processos costumam fluir através do canal, sendo realizado em diferentes pontos no tempo por diferentes membros do canal". Esses fluxos do canal são tarefas de trabalho executadas por membros do canal (intermediários), sendo que determinados produtos e serviços demandam pertinente complexidade entre empresas (montante e jusante), mas que facilitam a troca com os usuários finais (Frazier, 1999; Nevins, \& Money, 2007; Coelho, \& Easingwood, 2007). Esses fluxos dentro do canal de marketing são: de produto, de negociação, de propriedade, de informação e de promoção. Os fluxos são administrados de forma a alcançar os objetivos organizacionais (Coughlan et al., 2012), de forma a gerar vantagem competitiva, se contrastando com o mix produto, preço e promoção.

\subsection{Estrutura do canal e estratégia de distribuição}

Kotler e Keller (2013, p. 474) destacam a relevância do intermediário na incumbência de "obtenção de informações, negociação, formalização de pedidos, financiamento, posse física, pagamento e transferência de propriedade, além da necessidade de assumir os riscos". Larentis e Slongo (2008, p. 209) defendem que "uma empresa, por si só, não consegue, na maioria das vezes, distribuir seus produtos para os seus mercados-alvo". E ainda ratificam que "o modo como os canais de distribuição são concebidos depende, diretamente, da estratégia competitiva de atuação da empresa". Conforme Rosenbloom (2002) e Yanaze (2012), quanto à estrutura do canal, talvez o assunto mais discutido seja sua extensão, ou seja, o número de níveis de intermediários dentro do canal de marketing (figura 1).

$\underline{0}$

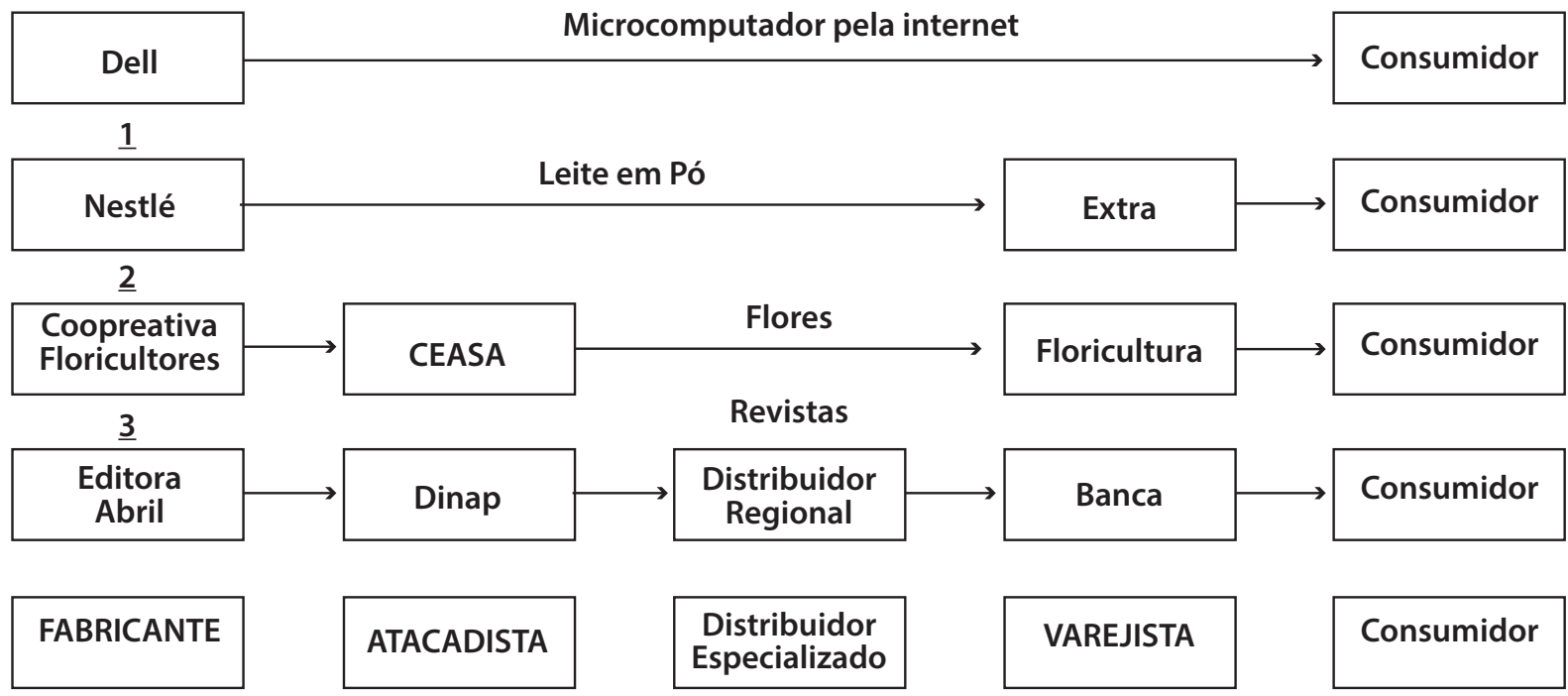

Figura 1 - Exemplos de Intermediários Fonte: Yanaze (2012, p. 405)

Em estratégia de distribuição, empresas adotam canais de distribuição com o propósito de garantir a disponibilidade dos produtos nos locais de consumo, ampliando o potencial de vendas, de forma a proporcionar visibilidade de demanda (Novaes, 2001). Conforme Ballou (1993, p. 49) "conseguir demanda é o resultado dos esforços promocionais, assim como o preço, e da composição de carteira de produtos oferecidos ao público. Uma vez conseguida a demanda, esta deve ser atendida e é quando a distribuição física age".

De acordo com Yanaze (2012), esse esforço pode ser alcançado por intermediários entre o fabricante e o cliente final de duas formas: canais comerciais e os de distribuição. Intermediários podem criar valor, individualizando os bens e serviços em relação à concorrência, de forma que o fabricante possa concentrar seus esforços e competência em seu negócio principal (Yanaze, 2012). Segundo o autor, "os canais de distribuição realizam as atividades de transporte, estocagem, armazenamento, serviços de bancos, financiadoras, entre outros que criam valor no processo, facilitando o deslocamento" (Yanaze, 2012, p. 389). Já os canais comerciais são divididos entre os que adquirem o produto (atacado e varejo) e os que não adquirem o produto (representante de vendas, atravessadores, agências de turismo, corretores), conforme ilustra a figura 2. 


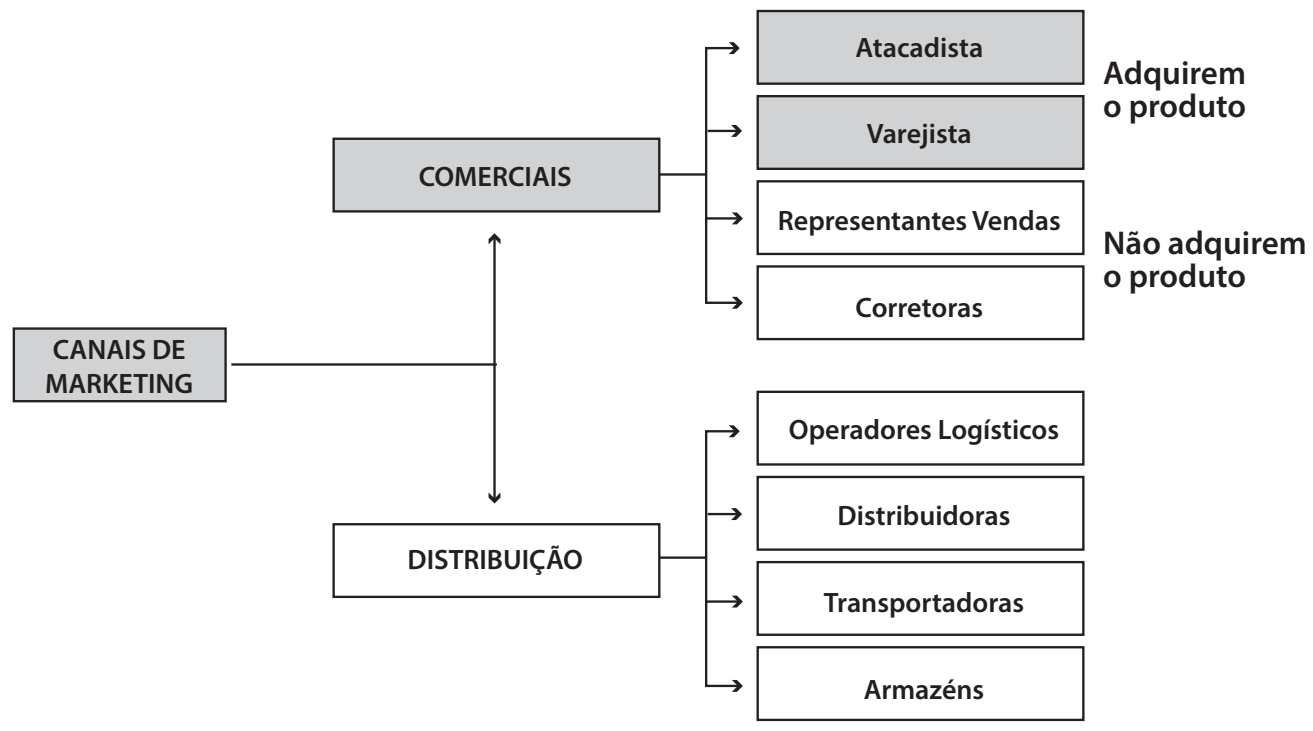

Figura 2 - Canais de vendas

Fonte: Adaptado de Yanaze (2012, p. 403)

Embora alguns fabricantes tendam a pensar que mais cobertura é sempre melhor, os varejistas preferem que o fabricante ofereça menos cobertura, segundo afirmação de Coughlan et al. (2012, p. 111). Todavia, os varejistas estão em melhor posição para compreender cada uma das necessidades dos usuários finais (Pelton, Strutton, \& Lumpkin, 2007) e se desenvolvem em ambientes competitivos por intermédio da relação com membros no canal de distribuição (Young, \&Wilkinson, 1989) com um conflito ou outro.

Nesse ponto de vista, Kotler e Keller (2013) asseguram que um conflito ou outro sempre ocorrerá entre empresas dentro do canal de distribuição, pois os interesses delas nem sempre coincidem, ainda mais quando dois ou mais canais vendem para o mesmo mercado. Entretanto, essa competição pode gerar posicionamento para a marca, uma vez que o varejista está em busca de melhores resultados e meios (Porter, 2002) para gerar mais valor percebido pelo cliente (Hooley, \& Saunders, 1996), oferecendo serviços agregados ao produto, tais como experiência profissional e serviço dedicado, por exemplo.

\subsection{Importância dos intermediários}

Todo membro classificado como atacadista, distribuidor especializado ou varejista é intermediário, inclusive empresas independentes, com diversas funções, entre elas, a de oferecer suporte aos fabricantes e aos usuários finais (Rosenbloom, 2002, Coughlan et al., 2012). Segundo Rosenbloom (2002, p. 75), varejistas têm como umas das principais funções a de "interpretar as demandas" e "estocar os bens que estes clientes quiserem, quando eles quiserem, e da forma que eles quiserem", bem como, na "variedade certa na hora certa que os clientes estão prontos para comprar".

Nesse sentido, os varejistas são capazes de fortalecer de forma positiva o marketing do produto / serviço quando este possui mais prestígio e reputação que o fabricante, lapidando consideravelmente a credibilidade do mesmo (Rosenbloom, 2002). Conforme estudo realizado por Sanematsu e Souza (2014), varejistas que usufruem de reputação e prestígio perante o cliente final (pela qualidade do produto do fabricante, aliada à experiência profissional e atendimento dedicado do varejista), culminam por propiciar posicionamento de marca do fabricante (figura 3). 


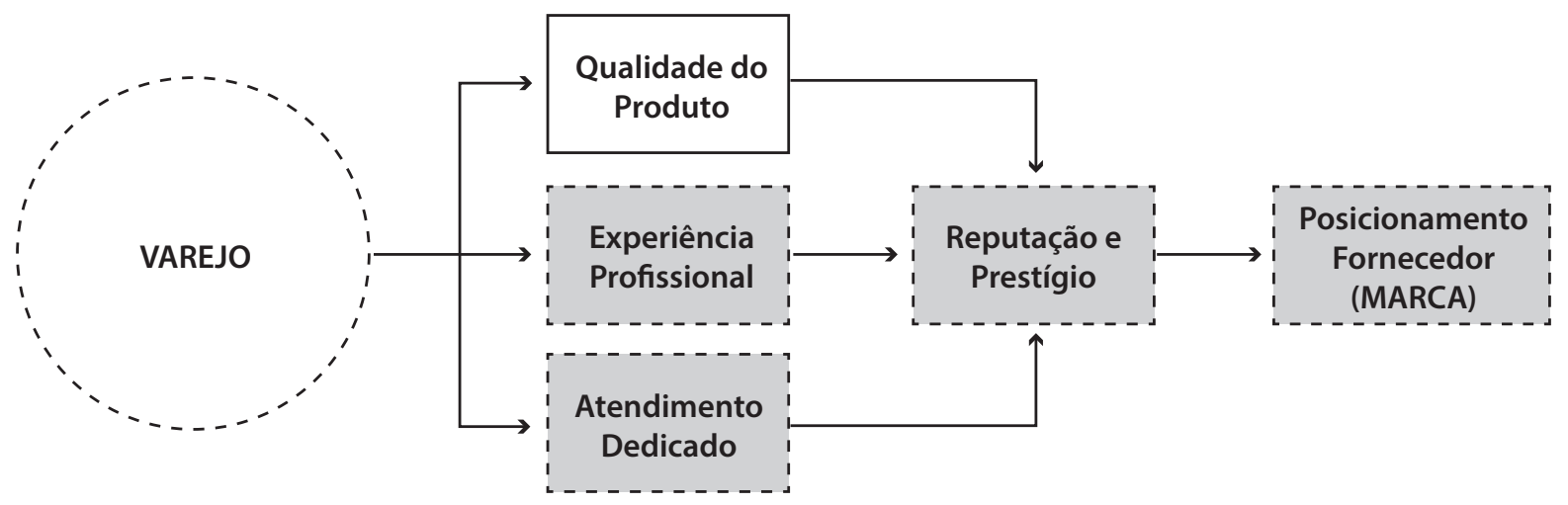

Figura 3 - Crescente poder dos varejistas no posicionamento de marcas Fonte: Adaptado de Sanematsu e Souza (2014)

Assim, quando fabricantes passam a ter "opiniões fortes sobre como os membros do canal devem lidar com suas marcas" (Coughlan et al., 2012, p. 94), opondo-se às ações de marketing do varejista, este último tende a trabalhar de forma independente. Na perspectiva dos fabricantes, "essa nova posição dos varejistas são potencialmente ameaçadoras" (Rosenbloom, 2002, p. 75) pois o varejista atende, facilita e se relaciona com o cliente, por meio do conjunto de ações e atitudes das pessoas (Spiller, Plá, Luz, \& Sá, 2011).

Ainda segundo Rosenbloom (2002, p. 78) "à medida que os varejistas continuarem a crescer, a se sofisticar tecnologicamente e abraçar o conceito de marketing, eles terão um papel ainda mais independente e dominante dentro do canal de marketing".

\title{
2.5 A Teoria dos 3 Puts
}

Yanaze (2012) argumenta que a Teoria dos 3 Puts tem como essência que os conceitos de marketing podem e devem ser aplicados também no plano interno na empresa (throughputs), fornecedores (inputs) e que a adequação dos anteriores se refletem no desempenho da empresa. Segundo o autor, a compreensão da Teoria dos 3 Puts (inputs, throughputs e outputs) é fundamental para as aplicabilidades de marketing em seu lado prático, visando máxima integração de uma empresa, dedicação ao mercado consumidor (varejista), bem como ao mercado fornecedor. Para o referido autor, marketing passa a ser uma atividade de toda a empresa, responsabilizando todos os envolvidos (fornecedor, empresa, 4Ps), de forma sistêmica, com o objetivo de atender de forma adequada e equilibrada demandas e condições de mercado. Nesse sentido, qualquer problema que ocorra nos inputs ou nos throughputs impactará diretamente no output (os 4Ps no varejista). $O$ autor continua:

\begin{abstract}
A batalha mercadológica de diferenciação entre empresas, hoje, não se restringe ao que elas oferecem ao mercado em termos de qualidade e adequação dos outputs, mas está fortemente migrando para o confronto de percepções que os diferentes públicos têm em relação a seus inputs e throughputs. Assim, o marketing contemporâneo exige das empresas uma ação efetiva na criação, na manutenção e na comunicação dos inputs e throughputs diferenciados, apropriados e que se constituam em fatos comunicáveis, contribuindo para a formação de imagem e reputação positivas (Yanaze, 2012, p. 56).
\end{abstract}

Assim, as empresas se organizam no que vão oferecer ao mercado (outputs: produto/serviço, preço/ remuneração, distribuição/vendas e comunicação), e se organizam também nos throughputs (estrutura, funcional, operacional para cumprir processos, sistemas, políticas, cultura e clima organizacional, logística). Não menos importantes, merecem destaque também os inputs, ou seja, os fornecedores (capital, colaboradores, infraestrutura, equipamentos, insumos, matéria-prima, informações e tecnologia). Nessa sequência, Yanaze (2012, p. 57) orienta que

Atentar somente aos próprios interesses organizacionais ou atender obstinadamente apenas as demandas do mercado constituem-se em decisões conflituosas comuns à grande maioria das empresas. Então que decisão tomar? A decisão correta da empresa deve ser aquela que contempla o equilíbrio da relação [...].

É crucial identificar as expectativas e necessidades tanto da empresa quanto do mercado, com decisões que busquem o equilíbrio para que a empresa programe uma forma eficaz de gestão, conforme ilustrado na figura 4 . Ainda segundo o autor, os conceitos de marketing surtirão efeito desejável quando cada setor se conscientizar de que suas atribuições específicas estão em função do atendimento das necessidades e das expectativas de outros setores dentro da empresa, e vice-versa (Yanaze, 2007, p. 57). 


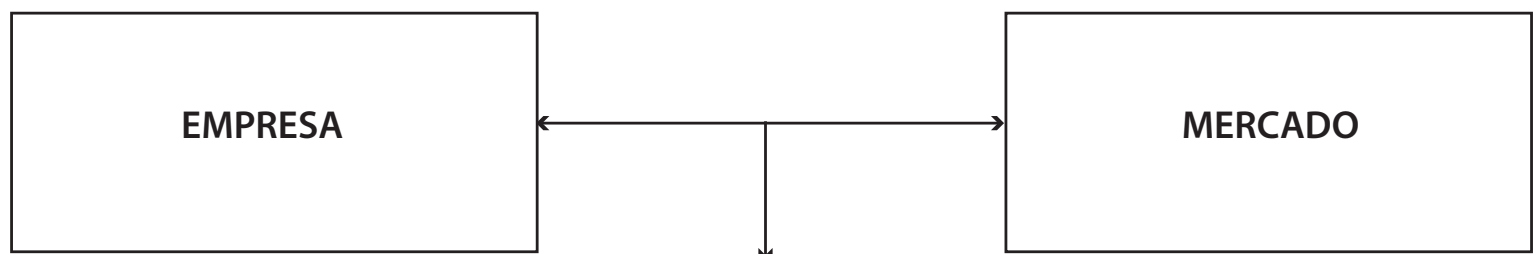

\section{Necessidades Expectativas Capacidade Pontencial}

\section{Equilibrio leva à Gestão Eficaz}

\section{Necessidades Expectativas Capacidade Pontencial}

Figura 4 - Relação de equilíbrio entre empresa e mercado Fonte: Adaptado de Yanaze (2012, p.57)

\subsection{Motivos para a aliança estratégica dentro dos canais de marketing}

Alianças estratégicas e relações dentro do canal de marketing têm sido dos temas mais pesquisados, conforme apontam Gulati (1998), Heimeriks e Duysters (2007) e Werner (2002). Segundo Coughlan et al. (2012, p. 217), "uma aliança é estratégica quando as conexões que vinculam as organizações são duradouras e substanciais, permeando vários aspectos de cada negócio". Ainda segundo o autor, "muitas alianças são mais bem coordenadas do que canais que são verticalmente integrados". Para atender à natureza do termo da aliança estratégica, a conduta dos membros do canal de marketing é alterada de forma a influírem juntos pelos mesmos objetivos.

Na perspectiva do fabricante, a aliança estratégica se torna interessante a partir do momento em que ele percebe que consegue mais lucro com determinado varejista do que com o que outro tenha a oferecer, pelo menos a princípio (Coughlan et al., 2012). Os fabricantes esperam obter informações de mercado (Fein, \& Jap, 1999) por meio de parceiros comprometidos, podendo ser alguns deles, poderosas organizações com reputação e prestígio, ou sendo alguns deles formadores de opiniões a respeito da qualidade do produto (Sanematsu, \& Souza, 2014). Os fabricantes precisam de uma aliança com varejistas que realizem os fluxos de produto, de negociação, de propriedade, de informação e de promoção (Rosenbloom, 2002) bem como os representem em seus mercados atuais, novos mercados e em lançamentos (Yanaze, 2012). Porém, Frazier (1999) realça que alguns fabricantes têm uma cultura interna que os impedem de compreender, respeitar e confiar nos intermediários.

Por sua vez, os varejistas arquitetam alianças com o objetivo de ter um suprimento seguro e estável de produtos desejáveis em alguns casos vindo a se consolidar varejista e fabricante por meio de fusão e aquisições (Coughlan et al., 2012). Varejistas também desenvolvem alianças para tornarem seus esforços de marketing mais bem-sucedidos. Um dos motivos para formarem aliança está relacionado à coordenação de esforços de marketing em conjunto para que o fabricante participe ativamente, gerando vantagem competitiva e duradoura.

Outra justificativa citada por diversos autores é a capacidade de gerar coesão, redução de custos, agregar valor ao produto / serviço ou aumento das vendas (Ansoff, 1988, Porter, 1988, Kotler, 1993, Kato, 2004), de forma a atender melhor aos clientes e aumentar as oportunidades (Coughlan et al., 2012), tal qual ilustra a figura 5.

\begin{tabular}{|l|l|l|}
\hline $\begin{array}{l}\text { Motivos para se aliar } \\
\text { estrategicamente }\end{array}$ & $\begin{array}{l}\text { O membro do canal a montante } \\
\text { (FABRICANTE) }\end{array}$ & $\begin{array}{l}\text { O membro do canal a jusante } \\
\text { (VAREJISTA) }\end{array}$ \\
\hline Fundamentos & $\begin{array}{l}\text { Motivar membros do canal a } \\
\text { jusante a representá-los melhor. }\end{array}$ & $\begin{array}{l}\text { Evitar faltas de estoques } \\
\text { enquanto se mantêm custos sob } \\
\text { controle. }\end{array}$ \\
\cline { 2 - 3 } & $\begin{array}{l}\text { - Em mercados atuais. } \\
\text { - Com produtos atuais. } \\
\text { - Em novos mercados. } \\
\text { - Com novos produtos }\end{array}$ & $\begin{array}{l}\text { fluxos executados, como menos os des } \\
\text { custos de manutenção. }\end{array}$ \\
\hline
\end{tabular}




\begin{tabular}{|c|c|c|}
\hline \multirow[t]{2}{*}{ Gerar preferência do cliente } & $\begin{array}{l}\text { Coordenar esforços de marketing } \\
\text { mais estreitamente com } \\
\text { membros do canal a jusante. }\end{array}$ & $\begin{array}{l}\text { Coordenar esforços de marketing } \\
\text { mais estreitamente com } \\
\text { membros do canal a montante. }\end{array}$ \\
\hline & $\begin{array}{l}\text { - Aproximar-se de clientes e } \\
\text { consumidores em potencial. } \\
\text { Melhorar a compreensão do } \\
\text { mercado. }\end{array}$ & $\begin{array}{l}\text { - Atender melhor ao cliente. } \\
\text { Converter consumidores em } \\
\text { potenciais clientes. Efeito líquido: } \\
\text { maior volume e margens }\end{array}$ \\
\hline \multirow[t]{2}{*}{$\begin{array}{l}\text { Preservar escolha e flexibilidade } \\
\text { de parceiros de canal }\end{array}$} & $\begin{array}{l}\text { Garantir acesso ao mercado } \\
\text { em face da consolidação no } \\
\text { comércio atacadista. }\end{array}$ & $\begin{array}{l}\text { Assegurar abastecimento } \\
\text { estável de produtos desejáveis } \\
\text { enquanto fabricantes se } \\
\text { consolidam. }\end{array}$ \\
\hline & $\begin{array}{l}\text { - Manter aberta as rotas para o } \\
\text { mercado } \\
\text { - Reequilibrar poder entre } \\
\text { produtor e canais } \\
\text { sobreviventes. }\end{array}$ & $\begin{array}{l}\text { - Em mercados atuais. } \\
\text { - Vendendo produtos atuais. } \\
\text { - Abrindo-se a novos mercados. } \\
\text { - Com novos produtos. }\end{array}$ \\
\hline \multirow[t]{2}{*}{ Antecipação estratégica } & $\begin{array}{l}\text { Erguer barreiras à entrada } \\
\text { de outras marcas. }\end{array}$ & $\begin{array}{l}\text { Diferenciar-se de outros } \\
\text { membros do canal a jusante. }\end{array}$ \\
\hline & $\begin{array}{l}\text { - Induzir canais a recusar acesso. } \\
\text { - Induzir canais a oferecer baixo } \\
\text { níveis de apoio a concorrentes. }\end{array}$ & $\begin{array}{l}\text { - Pontos de escoamento } \\
\text { preferenciais do } \\
\text { fornecedor. } \\
\text { - Serviços de valor agregado, } \\
\text { difíceis de copiar e alto valor para } \\
\text { o cliente }\end{array}$ \\
\hline \multirow[t]{2}{*}{ Meta superior } & $\begin{array}{l}\text { Vantagem competitiva } \\
\text { duradoura, que leva ao lucro. }\end{array}$ & $\begin{array}{l}\text { Vantagem competitiva } \\
\text { duradoura, que leva ao lucro. }\end{array}$ \\
\hline & $\begin{array}{l}\text { - Reduzir custos contábeis } \\
\text { e de oportunidade. }\end{array}$ & $\begin{array}{l}\text { - Reduzir custos contábeis } \\
\text { e de oportunidade. }\end{array}$ \\
\hline
\end{tabular}

Figura 5 - Motivos para criar e manter alianças estratégicas em canais.

Fonte: Adaptado de Coughlan et al. (2002, p. 224).

\subsection{Vinculação entre os membros (montante-jusante-montante)}

Antes do fabricante realizar qualquer tipo de investimento (relacionamento, por exemplo), deve verificar com rigor tanto a capacidade como a motivação do varejista em relação à aliança estratégica (Stump, \& Heide, 1996). Conforme Coughlan et al. (2012), quando viabilizado, o fabricante investe em treinamento, fusão da imagem da marca do fabricante com a imagem do distribuidor, entre outros. Esses investimentos dedicados são realizados com varejistas selecionados, tendo como objetivo aumentar o faturamento e ter acesso a informações do mercado atendido pelo varejista. Já o varejista entra na relação quando acredita que os investimentos (na relação, por exemplo) compensarão os custos (tempo de maturação, por exemplo). Isso leva a crer que o varejista espera retorno de forma a demandar recursos, tais como pessoal dedicado, marketing conjunto, entre outros (Jap, 1999). Quando o varejista se vincula ao fabricante, "permite-lhe conhecer seus pontos fracos, bem como os fortes, e fazer-Ihe recomendações" (Coughlan et al., 2012, p. 230).

\subsection{0 papel da satisfação econômica e não econômica nos canais de marketing}

Segundo Coughlan et al. (2012, p. 234), os "membros do canal se comprometem na expectativa racional de obter recompensas financeiras". Segundo os autores, eles não se comprometerão sem ao menos ter uma possibilidade de retorno financeiro, nem esperarão por esse resultado ao longo do tempo. Para que o relacionamento de comprometimento crie e mantenha o sentimento de confiança dentro do canal de marketing, é necessário que a satisfação econômica aconteça, pois desempenha um papel fundamental (Ganesan, 1994). A satisfação econômica também é vista como uma resposta afetiva positiva e emocional, gerada por um relacionamento dentro do canal (Coughlan et al., 2012). Logo, a satisfação econômica gera confiança que, por sua vez, constrói alianças. 
Embora o desempenho econômico seja a causa e efeito de relacionamentos comprometidos, ou seja, necessita de resultados para formar uma aliança, por outro lado, a confiança está associada a outras propriedades, sendo que algumas delas têm relação com o estado psicológico de satisfação não econômica, de forma afetiva positiva e emocional com aspectos psicossociais do relacionamento (Geysken, Steenkamp, \& Kumar, 1999). Coughlan et al. (2012, p. 235), afirmam que "um membro do canal satisfeito considera as interações como parceria de canal satisfatória, gratificante e fácil. Um membro de canal satisfeito gosta de trabalhar com seu parceiro e o percebe como interessado, respeitoso e disposto a trocar ideias (comunicação de duas vias)". Ainda, segundo os autores, a satisfação pode ser de forma interpessoal, bem como interorganizacional (interações diárias entre as pessoas do canal). No entanto, "seguidos estudos demonstram que a satisfação não econômica tem forte ligação com a confiança [...], que por sua vez é crucial à formação de alianças financeiramente desejáveis" (Coughlan et al., 2012, p. 235).

\section{PROCEDIMENTOS METODOLÓGICOS}

Para elaboração deste trabalho, assumiu-se uma abordagem qualitativa, de modo a, como sugerem Godoi, Bandeira-de-Mello e Silva (2010), identificar relações não imaginadas sobre determinado fenômeno. Optou-se por estudo exploratório (Gil, 2010) para se identificar possíveis fatores que influenciam o objeto (aliança estratégica dentro do canal de marketing, por exemplo) ou são por ele influenciados (o tempo transcorrido, busca por sobrevivência e expansão, por exemplo). Numa perspectiva longitudinal, considerou-se o período de 1995 a 2015 para análise da evolução das alianças estratégicas, a partir do ponto de vista do fabricante.

\subsection{Coleta de dados}

Os dados foram coletados por meio de entrevista baseada em roteiro semiestruturado e análise documental (Cassel, \& Simon, 2004; Pádua, 2012). Posto que os procedimentos de entrevista foram realizados no contexto organizacional, foi possível também fazer observação não participante. Utilizou-se a observação não participante de modo que o pesquisador entrasse em contato com o objeto de estudo, sem, no entanto, integrar-se a ele, agindo apenas como expectador (Marconi, \& Lakatos, 2011).

O primeiro contato com o entrevistado foi realizado por telefone e a entrevista foi agendada com um mês de antecedência. Participou da entrevista o gerente de vendas da empresa fabricante, por aproximadamente duas horas. O devido cuidado foi tomado, com consciência e preocupação face à ética de forma que a pesquisa não trouxesse nenhum prejuízo para o pesquisado e o pesquisador. Nesse sentido, foi realizada validação transacional (Oliveira, \& Piccinin, 2009), na qual o participante lê as respostas, de forma a ajustar ou confirmar os dados coletados frente à credibilidade e interpretação. Foi desenvolvido um protocolo de pesquisa com o propósito de aumentar a confiabilidade e a validade da pesquisa que, de acordo com Voss, Tsikriktsis e Frohlick (2002), serve como referencial de verificação para o pesquisador se certificar de que abordou todos os tópicos objetivados.

Quanto aos documentos, eles foram de origem primária e secundária, ou seja, produzido por pessoa que vivenciou diretamente o evento estudado, nesse caso a gerente de vendas da empresa fabricante pesquisada, onde trabalha há 20 anos. Outra análise foi a de forma secundária, ou seja, pelo acesso à base de dados e a outros tipos de registros públicos (Godoi et al., 2010).

\subsection{Apresentação da empresa fabricante}

A empresa fabrica filtros de reposição para automóveis, caminhões, colheitadeiras, motocicleta, ônibus, tratores, máquinas e equipamentos, estando no mercado brasileiro há mais de meio século, com uma capacidade de produção próxima a dez milhões de filtros/mês.

Com os dados secundários, foi possível identificar que a empresa pesquisada possui ampla gama de modelos de filtros de óleo de motor, totalizando 190 modelos sendo; 50 para automóveis, 20 para caminhões, 10 para motocicletas, entre outros. Atendendo ao pedido do gerente entrevistado, o nome da empresa não será divulgado.

\subsection{Apresentação do varejista}

Foi escolhida também como objeto de estudo uma empresa varejista, cliente do fabricante. Para definir a representatividade da empresa varejista, considerou-se o fato de ser a melhor colocada em relação à participação de mercado, na opinião do fabricante, bem como, a existência de sintomas de aliança estratégica entre membros do canal de distribuição. A empresa está localizada em uma cidade do interior do Estado de São Paulo, e comercializa três marcas de filtros de óleo de motor, sendo uma delas, a do próprio fabricante. A empresa 
concorre diretamente com outros 5 postos de gasolina, 16 oficinas e 1 loja de autopeças.

\section{APRESENTAÇÃO DE DADOS E DISCUSSÃO}

\subsection{Abordagem da aliança estratégica entre fabricante e varejista: ano de 1995}

De acordo com entrevistado, a relação de comprometimento teve início em 1995, face às particularidades e necessidades da época, sendo que o fabricante precisava obter informações de mercado (Fein, \& Jap, 1999) enquanto que o varejista precisa ter um suprimento seguro e estável (Coughlan et al., 2012).

O fabricante percebeu que poderia conseguir mais lucro com varejistas que gozassem de prestígio e reputação se comparados com outros membros do canal à jusante (Sanematsu, \& Souza, 2014). Já em relação às razões que levaram ao comprometimento do varejista com o fabricante naquela época, foi destacada a sinergia, redução de custos e aumento de vendas (Ansoff, 1988, Porter, 1988, Kotler, 1993, Kato, 2004).

Ainda no início, o foco da relação se instalou pelas necessidades de ambos tendo como cerne a melhor margem de lucro (quadro 2), ou seja, a recompensa financeira (Coughlan et al., 2012), de modo que eles se apoiaram na aliança estratégica para alcançar seus objetivos organizacionais independentes sendo que alguns circulavam de forma satélite (McCarthy, \& Perreault, 1997; Churchill Jr., \& Peter, 2000; Dickson, 2001; Berkowitz, 2003; Limeira, 2003; Blythe, \& Zimmerman, 2005; Kotler, \& Keller, 2013).

No passado, ambos convergiram na busca pela criação de "posição competitiva exclusiva e sustentável" (Porter, 2002, p. 28), de forma que se planejavam e organizavam, controlando o relacionamento (Miranda, \& Joshi, 2003), valorizando a cultura de compreensão, respeito e confiança (figura 6), sendo que, alguns fabricantes tendem a não praticar essa relação (Frazier, 1999).

$1995 \longrightarrow$ Início do relacionamento

\begin{tabular}{|c|c|c|}
\hline FABRICANTE & & VAREJISTA \\
\hline \multirow{2}{*}{$\begin{array}{l}\text { Necessidade da Informação } \\
\text { de mercado }\end{array}$} & ABORDAGEM & \multirow{2}{*}{$\begin{array}{l}\text { Necessidade de suprimento } \\
\text { seguro e estável }\end{array}$} \\
\hline & \multirow{3}{*}{$\begin{array}{l}\text { Foco na recompensa } \\
\text { financeira/melhor } \\
\text { margem de lucro }\end{array}$} & \\
\hline $\begin{array}{l}\text { Necessidade em obter } \\
\text { melhores margens de lucro }\end{array}$ & & $\begin{array}{l}\text { Necessidade de sinergia no } \\
\text { canal e redução de custos }\end{array}$ \\
\hline $\begin{array}{l}\text { Buscar por varejista com } \\
\text { prestígio e reputação }\end{array}$ & & $\begin{array}{l}\text { Necessidade de aumento } \\
\text { das vendas }\end{array}$ \\
\hline
\end{tabular}

Figura 6 - Perspectiva do fabricante: ano de 1995

Fonte: Elaborado pelos autores

\subsection{Abordagem da aliança estratégica do fabricante e varejista: ano de 2015}

Em ambientes de rápidas mudanças mercadológicas, tão difícil quanto construir uma vantagem competitiva é sustentá-la (Sanematsu, \& Souza, 2014). Frente a este desafio, o fabricante observou, no decorrer dos 20 anos (1995-2015), que utilizar o canal de marketing (praça) gerava vantagem competitiva se comparado às estratégias de produto, preço e promoção (Rosenbloom, 2002). Em contrapartida, como competir com fabricantes que também utilizavam o canal de marketing (praça) como estratégia de negócio? Nesse sentido, surgiu a aliança estratégica como divisor de águas face à diferenciação entre os demais concorrentes que atuam no mesmo segmento, com a mesma estratégia (praça).

Ao indagar o entrevistado face ao planejamento, organização e controle da aliança estratégica como cerne nos canais de distribuição (Miranda, \& Joshi, 2003) nos dias atuais, o entrevistado afirmou que "é preciso trabalhar de tal forma que o cliente não cote preço, ligue e peça isso, e isso, e isso [...]". E seguindo, "tem que se planejar para atender os clientes, muito mais na forma relacional do que para vender, pois, com tecnologia você encontra qualquer produto em qualquer lugar [...]". Outro ponto importante observado na prática do entrevistado com o varejista é o fato de "ser honesto, o desconto é igual para todos esses clientes especiais e não trabalho com tabela fechada, faço valer a nossa amizade [...], eles sabem que são especiais".

O entrevistado afirmou que trabalha fortemente o suporte, pois "empresa que é boa dá suporte". Ao 
questionar o que seria suporte, ele esclareceu que não adianta vender e não entregar, "vendeu, tem que entregar e rápido". Ainda em suporte, o fabricante explica que terceirizou a logística de forma a agregar valor em um aspecto que o varejista valoriza; o prazo de recebimento da mercadoria (24 horas). Conforme o entrevistado, anteriormente a essa estratégia, o tempo médio de entrega era de 7 dias corridos (pois precisava formar carga), forçando o varejista a ter estoque, onerando em custo com espaço físico, bem como, necessidade de capital de giro. Nesse sentido, o fabricante criou valor, individualizando os bens e serviços em relação à concorrência (Yanaze, 2012).

Outro suporte relatado pelo entrevistado é o fato de que atualmente o fabricante controla o estoque do varejista, mas que" não pode empurrar produto pra bater meta, tem que vender (pra ele) o que ele precisa [...], hoje os clientes são mais amigos e o preço precisa ser justo". Assim, trabalhar de forma relacional requer atenção dedicada, demandando complexidades entre empresas (Frazier, 1999; Nevins, \& Money, 2007; Coelho, \& Easingwood, 2007), mas que tal esforço explicita a justiça e infere na geração de confiança.

Ainda sobre o controle de estoque do varejista por parte do fabricante, o entrevistado relatou que alguns objetivos são prever a demanda, garantir a disponibilidade do produto nos locais de consumo e aumentar o potencial de vendas para ambos (Novaes, 2001), mas que para tal propósito, os esforços promocionais são necessários; preço competitivo em relação aos concorrentes frente ao cliente final e variedade de produtos atendendo a todas as marcas e modelos de automóveis, tal qual defendem Ballou (1993) e Novaes (2001).

O entrevistado mencionou outra prática: "tem que ter contato, tem muita gente na rua, tem internet [...], o momento é difícil pra todos por conta da crise, inclusive até para os vendedores de sapatos". Foi possível observar na fala do entrevistado que as dificuldades passadas ou que passam atuam como mola propulsora para o aumento de contato entre membros dos canais (fabricante com o varejista) de forma a atuarem juntos pelos mesmos objetivos (Coughlan et al., 2012), formando alianças estratégicas, visando não só crescimento empresarial, mas também sobrevivência (Dickson, 2001).

Entre relacionamento (confiança) e custo de oportunidade (melhorar margem), foi observado que o fabricante define o varejista como seu cliente final, "envolvido no processo de disponibilizar um bem ou serviço para uso ou consumo" (Kotler, \& Keller, 2013, p. 448) e "que uma empresa, por si só, não consegue na maioria das vezes, distribuir seus produtos para os seus mercados-alvo", cenário semelhante ao apontado por Larentis e Slongo (2008, p. 209).

Em se tratando de aliança estratégica, a empresa fabricante passou atuar de forma integrada (Rosenbloom, 2002; Coughlan et al., 2012), compartilhada e aberta, com canal de comunicação de mão dupla, tendo no varejista seu cliente final (Frazier, 1999; Nevins, \& Money, 2007; Coelho, \& Easingwood, 2007), consciente de que suas ações, seja no fornecedor de matéria-prima (inputs) ou no âmbito organizacional interno (throughputs), têm impacto direto nos 4Ps (produto, preço, praça, promoção), ou seja, os outputs do varejista (Yanaze, 2012). $O$ entrevistado relatou um evento ocorrido no ano passado:

[...] quando soube que um dos nossos filtros estava vazando óleo de motor e ficou pingando na saída [...] caindo no escapamento quente do carro e virou fumaceira, parei tudo o que estava fazendo. A gente entendeu que o problema estava no anel de borracha do nosso filtro [...]. O cliente sabia que podia contar e que tem suporte, por isso ligou [...]. Sabe que a gente resolve mesmo quando o problema é do fornecedor. Nós não entregamos só qualidade de produto, mas também suporte pra diferenciar como estratégia do negócio. Esse formato está dando certo e pretendemos replicar dentro do canal.

\subsection{Satisfação econômica e não econômica}

Quando questionado o motivo que o leva a manter o relacionamento de comprometimento, o entrevistado afirmou que pretende fazer negócios com o varejista por muito tempo. Autores como Anderson e Barton (1992) defendem que o comprometimento é mais que um relacionamento formalizado, pois o varejista não tem nada em contrato quanto às vantagens e desvantagens da aliança estratégica dentro do canal de marketing, demonstrando o forte senso de lealdade entre eles. Importante enfatizar que, na visão do entrevistado, um ponto forte deste relacionamento face ao comprometimento e confiança está relacionado ao turnover zero, ou seja, o mesmo vendedor há 20 anos.

Segundo Coughlan et al. (2012, p. 234), os "membros do canal se comprometem na expectativa racional de obter recompensas financeiras", ou seja, para que o relacionamento de comprometimento se crie e se mantenha, é necessário que a satisfação econômica aconteça, pois desempenha um papel fundamental (Ganesan, 1994).

Durante a entrevista, foi possível inferir que o tempo transcorrido entre fabricante e varejista alicerçou a aliança estratégica de forma não econômica por parte do varejista. Corroborando com a inferência, "seguidos estudos demonstram que a satisfação não econômica tem forte ligação com a confiança" (Coughlan et al., 2012, p. 235). Nesse sentido, Geysken, Steenkamp e Kumar (1999) afirmam que a confiança está vinculada ao estado psicológico de satisfação não econômica de forma afetiva, positiva e emocional. A fala do entrevistado ilustra 
essa questão do vínculo:

\begin{abstract}
Mantenho o varejista informado de todas as novidades de mercado; quando o preço vai subir, se vai descer, qual modelo vai sair de linha, o que está chegando. É estranho dizer isso, mas tem que orientar para não comprar, às vezes... porque tem promoção chegando, por exemplo. Treinei o pessoal dele para vender e hoje o posto vende mais por causa do trocador de óleo que a gente continua treinando. O pessoal dele aprendeu a passar confiança aos clientes. Mesmo que ele suba o preço, os clientes continuam com eles. [...] O gerente do posto me disse que $99 \%$ das pessoas que trocam óleo, enchem o tanque e são 600 tanques por mês, só com os trocadores. Caminhão gasta mais. O posto ganha com isso, uns $15 \%$ de receita a mais. E a gente ganha também [...].
\end{abstract}

Segundo o entrevistado, a atuação do varejista está centrada no papel de suporte, mas de forma não econômica frente ao lucro da venda do produto em si, ou seja, valorizando outras satisfações, entre elas, a interação satisfatória, gratificante e fácil (Coughlan et al., 2012). Outra inferência na fala do entrevistado são os ganhos de $15 \%$ a mais na receita com vendas de combustível, quando mediadas pela venda e troca de filtro de óleo de motor.

Portanto, infere-se que, no segundo período (ano de 2015), o foco está centrado no suporte enfatizado por relacionamento e confiança (Geysken, Steenkamp, \& Kumar, 1999). A figura 7 mostra os resultados obtidos na pesquisa realizada entre fabricante e varejista, frente ao tema aliança estratégica dentro do canal de marketing, sob a perspectiva do fabricante de filtro de óleo de motor com varejista.

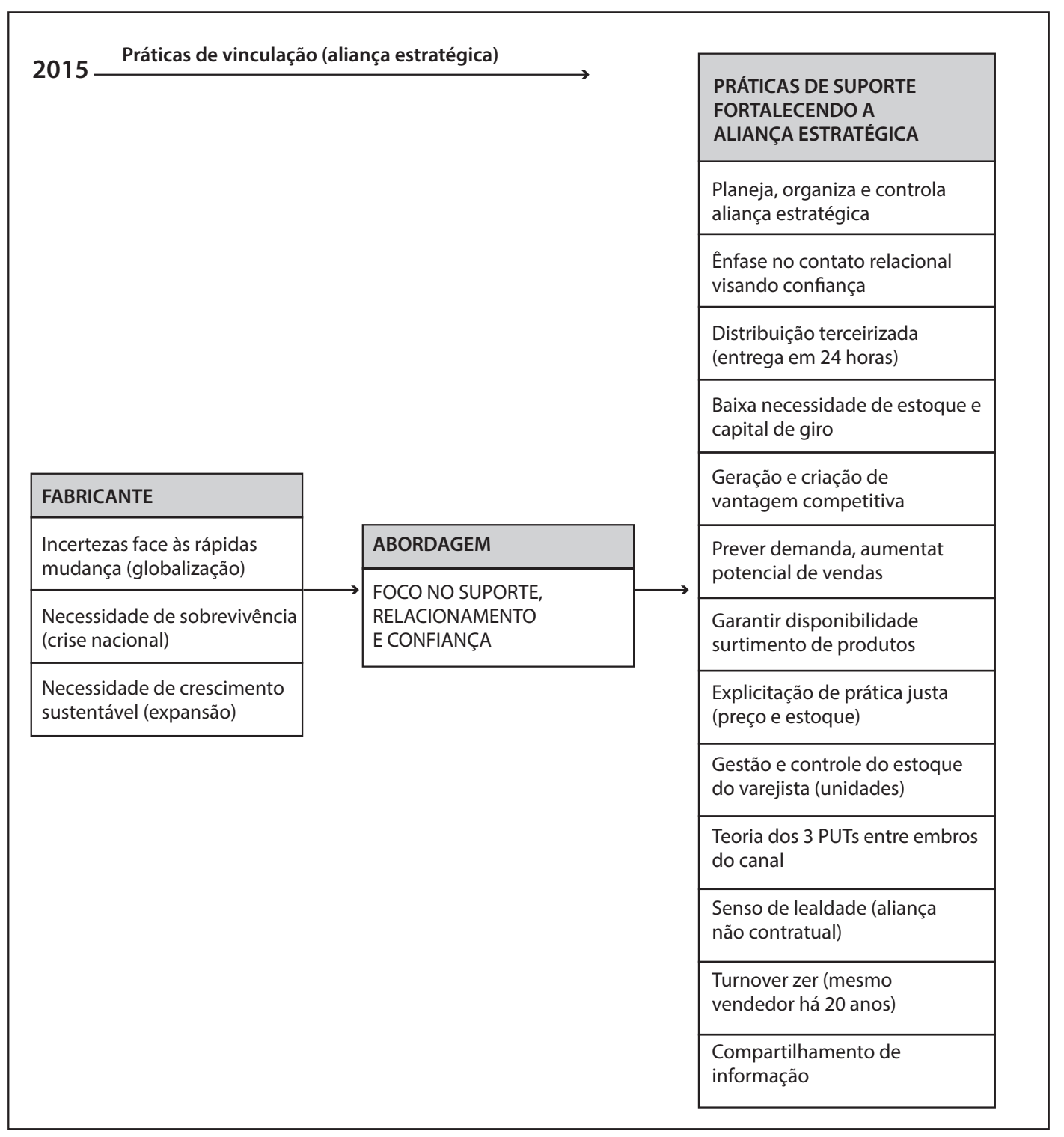

Figura 7 - Perspectiva do fabricante: ano de 2015.

Fonte: Elaborado pelos autores 


\section{CONSIDERAÇÕES FINAIS}

Segundo o entrevistado da empresa fabricante, o tempo transcorrido aportou uma curva de aprendizado com necessidades de adaptação, talhando novos formatos de aliança estratégica frente às rápidas mudanças para atender os objetivos organizacionais, sendo que uma delas passa a ser o relacionamento e a confiança (Geysken, Steenkamp, \& Kumar, 1999) entre os membros do canal como cerne competitivo, frente à sobrevivência e expansão dos negócios (Dickson, 2001), em vez de ser apenas a busca por melhores lucros e recompensas financeiras (Coughlan et al., 2012).

Para cunhar vínculo com o cliente frente à aliança estratégica, o fabricante terceirizou a logística física para atender com velocidade e precisão, para distribuir seus produtos no mercado-alvo, aumentando sua visibilidade e demanda. Retomou seu posicionamento de marca, uma vez que o varejista está em melhor posição para compreender as necessidades dos usuários finais, buscando meios para gerar valor percebido pelo cliente em ambientes competitivos (Young, \& Wilkinson, 1989).

Nesse sentido, este estudo proporcionou inferir também a mudança de foco por parte do varejista, uma vez que, anteriormente, a abordagem da aliança estratégica do fabricante para com o varejista e vice-versa, estava centrada na relação entre recompensa financeira e melhor margem de lucro (ano de 1995), e agora o foco está centrado na abordagem de suporte, relacionamento e confiança (ano de 2015), com o objetivo de vincular as organizações de forma duradora e substancial, gerando vantagem competitiva pela aliança estratégica dentro do canal de marketing entre fabricante e varejista, e vice-versa.

Ainda na questão da mudança no foco de abordagem da aliança estratégica, pode-se inferir que as incertezas mercadológicas provocadas pela globalização, necessidade de sobrevivência, bem como a busca de crescimento sustentável, moldou novas práticas e reflexões por parte do fabricante, de forma a olhar para o varejista como uma extensão de sua própria organização, visando máxima integração entre elas e contemplando o equilíbrio na relação, coordenando seus esforços de marketing em conjunto frente às oportunidades e ameaças.

Este trabalho evidenciou dois aspectos que diferem da literatura adotada como referência, sendo que, no primeiro, o fabricante valoriza a cultura de compreensão, respeito e confiança (mediado pela cultura interna), enquanto que outros tendem a não praticar essa relação (Frazier, 1999). Já no segundo, é a afirmação que "membros do canal se comprometem na expectativa racional de obter recompensas financeiras", por Coughlan et al. (2012, p. 234), mas constatou-se, nesta pesquisa, que a recompensa financeira não desempenha papel fundamental na aliança estratégica para o varejista, se comparada com suporte, relacionamento e confiança.

O estudo aqui apresentado tem limitações por ter adotado apenas um cenário organizacional como foco de investigação, fato que impede generalizações. Outra limitação reside na opção por um tipo de abordagem metodológica (qualitativa), de modo que se sugere, para estudos futuros, investigações semelhantes com abordagens quantitativas, além da extensão do campo organizacional estudado (outras empresas, segmentos etc.).

\section{REFERÊNCIAS}

Ansoff, I. (1988). Corporate strategy. London: Penguin Books.

Ballou, R. H. (1993). Logística empresarial. São Paulo: Atlas.

Berkowitz, E. N. (2003). Marketing. Rio de Janeiro: LTC.

Blythe, J., \& Zimmerman, A. (2005). Business-to-business marketing management: a global perspective. London: Thomson Learning.

Cassell, C., \& Symon, G. (2004). Essential Guide to Qualitative Methods in Organizational Research. London: Sage Publications.

Churchill Jr., G. A., \& Peter, J. P. (2000). Marketing: criando valor para o cliente. São Paulo: Saraiva.

Coelho, F., \& Easingwood, C. (2007). An exploratory study into the drivers of channel change. European Journal of Marketing, 42(9), 1005-1022.

Coughlan, A. T., Anderson, E., Stern, L. W., \& El-Ansary, A. I. (2012). Canais de marketing. São Paulo: Pearson Education.

Dickson, P. R. (2001). Introdução ao marketing: In M. R. Czinkota (Ed.), Marketing: as melhores práticas (Parte 1). Porto Alegre: Bookman.

Frazier, G. L. (1999). Organizing and Managing Channels of Distribution. Journal of the Academy of Marketing Science, 27(2), 226-240. 
Fein, A. J., \& Jap, D. (1999). Manage Consolidation in the Distribution Channel. Sloan Management Revew, 41(1), 6 61-72.

Ganesan, S. (1994). Determinants of long-term operation in buyer-seller relationship. Journal of Marketing, 58(2), 1-19.

Geysken, I., Steenkamp, J. B., \& Kumar, N. (1999). A meta-analysis of satisfaction in Marketing Channel Relationships. Journal of Marketing Research, 36(2), 223-238.

Gil, A. C. (2010). Como elaborar projetos de pesquisa. São Paulo: Atlas.

Godoi, C. K., Bandeira-De-Mello, R., \& Silva, A. B. (2010). Pesquisa qualitativa em estudos organizacionais: paradigmas, estratégias e métodos. São Paulo: Saraiva.

Gulati, R. (1998). Alliances and networks. Strategic Management Journal, 19(4), 293-317. Heimeriks, K., \& Duysters, G. (2007). Alliance capability as a mediator between experience and alliance performance: an empirical investigation into the alliance capability development process. Journal of Management Studies, 44(1), 25-49.

Hooley, G. J., \& Saunders, J. (1996). Posicionamento competitivo: como estabelecer e manter uma estratégia de marketing no mercado. São Paulo: Makron Books.

Jap, S. D. (1999). Pie-Expansion'Efforts: Collaboration Processes in Buyer-Supplier Relationships. Journal of Marketing Research, 36(4), 461-475.

Kato, H. T. (2004). Estratégia e canais de marketing. Revista de Administração UNISAL, 1, 1-20.

Kotler, P. (1993). Princípios de marketing. Rio de Janeiro: Prentice Hall.

Kotler, P., \& Keller, K. L. (2013). Administração de marketing. São Paulo: Pearson Education.

Larentis, F., \& Slongo, L. A. (2008). Relacionamento em Canais de Marketing como Fonte de Vantagem

Competitiva Sustentável: Um Estudo com Fabricantes de Moveis e Lojas Exclusivas. Rev. Adm., 43(3), 209-223.

Limeira, T. M. V. (2003). Fundamentos de marketing. In S.R. Dias (Coord.). Gestão de Marketing. São Paulo: Saraiva.

Marconi, M. A., \& Lakatos, E. M. (2011). Metodologia Científica. São Paulo: Atlas.

McCarthy, E. J., \& Perreault Jr., W. D. (1997). Marketing essencial: uma abordagem gerencial e global. São Paulo: Atlas.

Miranda, M., \& Joshi, M. (2003). Australian retailer need to engage with private labels to achieve competitive difference. Asian Pacific Journal of marketing and Logistics, 51(3), 34-48.

Nevins, L. J., \& Money, R. B. (2008). Performance implications of distributor effectiveness, trust, and culture in import channels of distribution. Industrial Marketing Management, 37, 46-58.

Novaes, A. G. (2001). Logística e gerenciamento da cadeia de distribuição. Rio de Janeiro: Campus.

Oliveira, S. R., \& Piccinin, V. C. (2009). Validade e flexibilidade na pesquisa qualitativa. Cadernos EBAPE. BR, 7(1), 9098.

Pádua, E. M. M. (2012). Metodologia de pesquisa: abordagem teórico-prática. São Paulo: Papiros.

Pelton, L. E., Strutton. D., \& Lumpkin, J. R. (2007). Marketing Channels: A Relationship Management Approach. Los Angeles: Times Mirror Books.

Porter, M. E. (1988). Competitive advantage. New York: The Free Press.

Porter, M. E. (2002). Os anos 90 acabaram... volte à estratégia! HSM Management / Expo Management 2001,30, 28-29.

Rosenbloom, B. (2002). Canais de marketing: uma visão gerencial. São Paulo: Atlas.

Sanematsu, L. S. A., \& Souza, T. A. (2014, Dezembro). O papel dos clientes varejistas em relação ao posicionamento de marca industrial: um estudo multicaso no setor de peças automotivas. In A. C. Francisco, A. A. Luz, L. M. Luz (Ed.), IV Congresso de Engenharia de Produção, Ponta Grossa, PR.

Spiller, E. S., Plá, D. R. H., Luz, J. F., \& Sá, P. R. G. (2011). Gestão de serviços e marketing interno. Rio de Janeiro: FGV.

Stump, R. L., \& Heide, J. B. (1996). Controlling Supplier Opportunism in Industrial Relations. Journal of Marketing Research, 33(4), 431-441.

Voss, C., Tsikriktsis, N., \& Frohlich, M. (2002). Case research in operations management. International Journal of Operations \& Production Management, 22(2), 195-219.

Werner, S. (2002). Recent developments in international management research: A review of 20 top management journals. Journal of Management, 28(3), 277-305.

Yanaze, M. Y. (2012). Gestão de marketing e comunicação: avanços e aplicações. São Paulo, Saraiva. 
Young, L. C., \& Wilkinson, F. I. (1989). The Role of Trust and Co-operation in Marketing Channels: A Preliminary Study. European Journal of Marketing, 23(2), 109-122. 